\title{
Endotracheal metastasis of hepatocellular carcinoma: a case report
}

\author{
Giacomo Ghinassi ${ }^{1^{* \dagger}}$, Pasquale Imitazione ${ }^{1^{* \dagger}}$, Alfonso Pecoraro ${ }^{2}$, Luciano B. G. Montella ${ }^{2}$ Paola Martucci ${ }^{2}$, \\ Raffaella Giacobbe ${ }^{2}$, Campione Severo ${ }^{3}$ and Domenico Aronne $^{2}$
}

\begin{abstract}
We describe the case of a 75 years old patient with a history of hepatocellular carcinoma, with acute respiratory failure due to tracheal obstruction by metastasis, successfully treated with airway disobstruction with rigid bronchoscope.
\end{abstract}

\section{Case report}

A 75 years old man, smoker, with a past history of a hepatic transplantation 13 years earlier for a hepatocellular carcinoma, was admitted to hospital with hemoptysis and dyspnea. He performed a chest CT scan, showing a solid lesion in the apical segment of right lower lobe with multiple confluent mediastinal adenopathies and right paratracheal lymphadenopathy (Fig. 1).

We practiced a videobronchoscopy that showed two small sessile lesions approximately $4.5 \mathrm{~cm}$ far from the carina on the right lateral wall of the trachea, which were removed with biopsy forceps. EBUS-TBNA was performed on the right paratracheal lymph node. The pathological findings were suggestive for hepatocarcinoma metastases and the patient was underwent chemotherapy.

After six months, the patient returned to the emergency room for wheezing and acute respiratory failure. Chest $\mathrm{x}$-ray and $\mathrm{CT}$ scan showed deterioration of the radiological picture with stenosis of the tracheal lumen (Fig. 2).
The patient made videobronchoscopy that showed a vegetative neoformation which obstructed the tracheal lumen about $6.5 \mathrm{~cm}$ far from the true vocal cords (Fig. 3). The patient was intubated with a rigid bronchoscope Storz $\mathrm{n}^{\circ} 14$ and we used laser photocoagulation to devascularize the lesion that was subsequently removed with a debulking maneuver, recanalizing the trachea (Fig. 4). The anatomopathological findings confirmed the previous diagnosis of hepatocarcinoma metastases (Fig. 5).

\section{Discussion and Conclusion}

The interest of this case is essentially due to two reasons: the rarity of the metastatic localization of hepatocellular carcinoma, which, as reported in the literature, has an incidence of $0.04 \%$ [1] and the importance of rigid bronchoscopy in the resolution of respiratory failure secondary to tracheal obstruction.

The lungs represent the most common site of liver metastases, reported in the $37-70 \%$ of cases at autopsy but less often clinically detected. These appear

\footnotetext{
* Correspondence: giacomo.ghinassi87@gmail.com; pasquale.imitazione@gmail.com

${ }^{\dagger}$ Giacomo Ghinassi and Pasquale Imitazione contributed equally to this work. ${ }^{1}$ Dipartimento di Medicina Clinica e Chirurgia, Sezione di Malattie dell'Apparato Respiratorio, Università Federico II, Monaldi hospital, via L. Bianchi, 80131 Naples, Italy

Full list of author information is available at the end of the article
} 


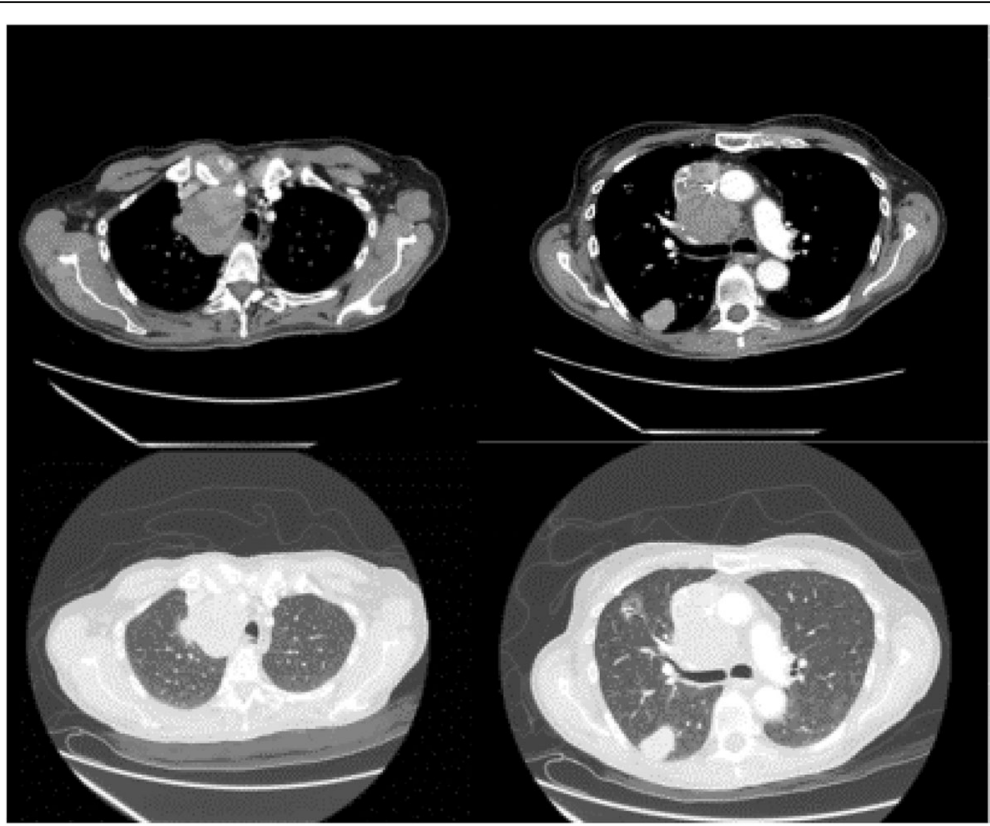

Fig. 1 Chest enhanced computed tomography $(C T)$ showed a solid lesion in the apical segment of right lower lobe with multiple confluent mediastinal adenopathies and right paratracheal lymphadenopathy

as nodules, often multiple and pleural effusion is common. Many nodules have the tendence to appear in the right-lower lobe, and the greatest degree of effusion occurs in the lower lobes, suggesting a probable transdiaphramatic spread. Occasionally, these metastases spread and give a miliary pattern [2]. Another possible mechanism is lymphatic spread, as probably happened to our patient. In fact mediastinal lymph nodes were involved since the tracheal lesion appeared.

Tracheal localization appears particularly important for the risk of incurring acute respiratory failure, as happened to our patient. Rigid bronchoscopic therapy is required for the treatment of patients with central airway obstruction. Various bronchoscopic techniques are available for tracheobronchial tumors, including

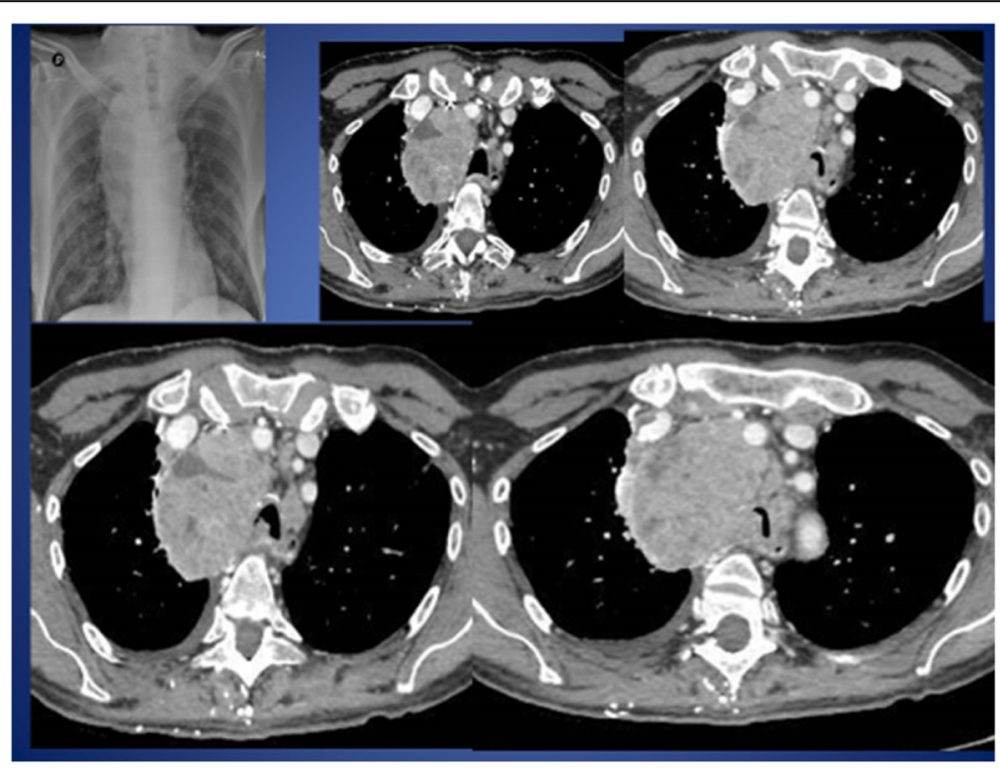

Fig. 2 Chest radiography and Computed Tomography $(\mathrm{CT})$ showed a solid neoplastic lesion in the apical segment of the right lower lobe and significant stenosis of the tracheal lumen 


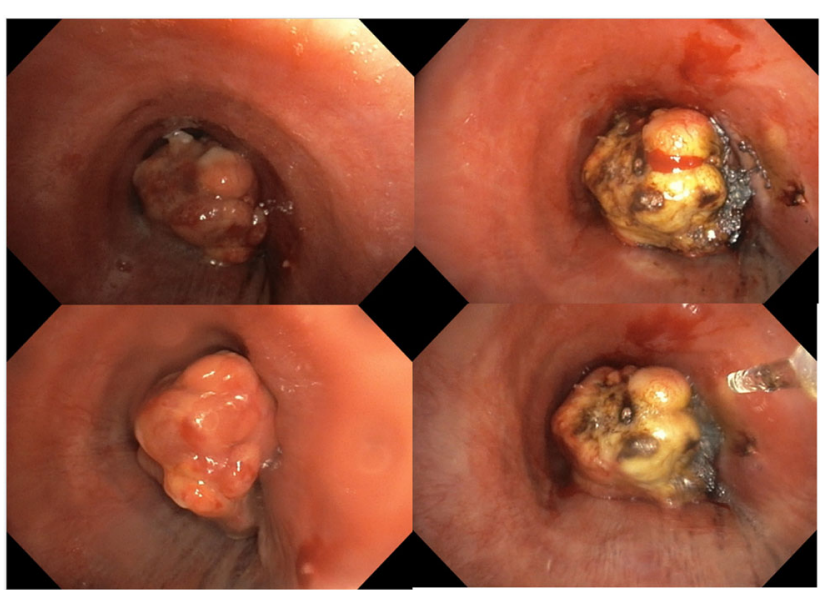

Fig. 3 Bronchoscopy revealed that the tumor completely obstructed the tracheal lumen

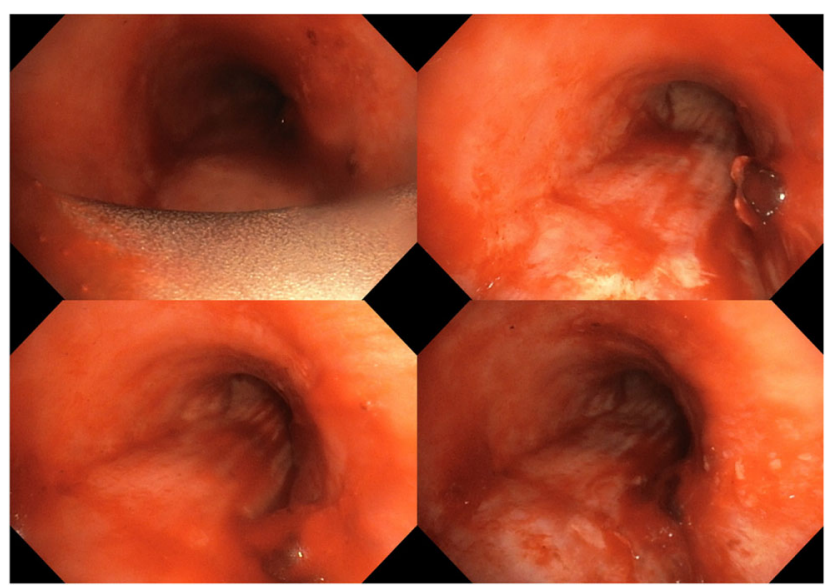

Fig. 4 After bronchial disobstruction, bronchoscopy revealed the recanalization of tracheal lumen
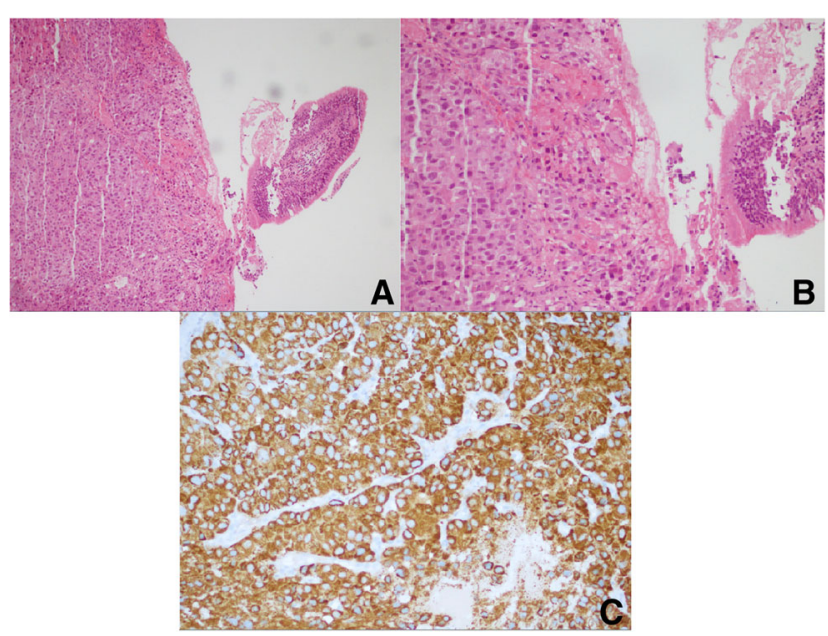

Fig. 5 a) 100 enlargements, hematoxylin and eosin. Solid-growth non-small cell epithelial neoplasia. On the right fragment of ciliated cylindrical epithelium of the respiratory tract; b) 200 enlargements, same field; c) 200 enlargements, immunohistochemical anti-hepatocyte antigen: diffuse cytoplasmic granular positivity according to the hepatic origin of the neoplasia (hepatocellular carcinoma) 
neodymium-yttrium-aluminum-garnet (Nd-YAG) laser therapy, electrocautery, brachytherapy, photodynamic therapy, cryotherapy, and APC [3].

In conclusion, interventional bronchoscopy in most cases of acute airway obstruction from cancer is palliation, not cure. Reestablishment of patient airways may avoid hospitalization in a critical care unit, prolonged intubation and mechanical ventilation, and enhances patient's ability to accept and undergo systemic chemotherapy, immunotherapy or radiation therapy [4]. It also determines an immediate symptomatic relief and an improvement in the quality of life $[5,6]$.

\section{Abbreviations}

APC: Argon Plasma Coagulation; CT: Computed Tomography; EBUSTBNA: Endobronchial Ultrasound Transbronchial Needle Aspiration

\section{Acknowledgements}

None.

\section{Funding}

The authors state that the case report was produced in the absence of economic founding sources.

\section{Registration of research studies}

Not applicable.

\section{Guarantors}

Giacomo Ghinassi, MD; Pasquale Imitazione, MD.

\section{Provenance and peer review}

Not commissioned, externally peer-reviewed.

\section{Authors' contributions}

GG and PI conceptualized the study, performed a literature review and drafted the manuscript. AP and LBGM performed a literature review and drafted the manuscript. PM and RG performed a literature review and collected data. DA critically revised the article. All authors read and the final manuscript.

\section{Ethics approval and consent to participate}

No ethical committee approval was required for this case report by the Department of Clinical Medicine and Surgery, Section of Respiratory

Diseases, Università Federico II, Monaldi hospital, Naples.

\section{Consent for publication}

Written informed consent was obtained from the patient for publication of this case report and accompanying images. A copy of the written consent is available for review by Editor-in-Chief of this journal on request.

\section{Competing interests}

There is no conflict of interest for any of the authors.

\section{Publisher's Note}

Springer Nature remains neutral with regard to jurisdictional claims in published maps and institutional affiliations.

\section{Author details}

'Dipartimento di Medicina Clinica e Chirurgia, Sezione di Malattie dell'Apparato Respiratorio, Università Federico II, Monaldi hospital, via L. Bianchi, 80131 Naples, Italy. ${ }^{2}$ Dipartimento Onco-pneumo-ematologico, Servizio di Endoscopia Bronchiale ed Urgenze broncologiche, Ospedale Antonio Cardarelli, Naples, Italy. ${ }^{3}$ Dipartimento di Anatomia Patologica, Ospedale Antonio Cardarelli, Naples, Italy.
Received: 21 January 2019 Accepted: 2 April 2019

Published online: 06 June 2019

References

1. Madariaga ML, Gaissert HA. Secondary tracheal tumors: a systematic review. Ann Cardiothorac Surg 2018;7(2):183-96.

2. Dail DH, Hammer SP. Pulmonary Pathology Second Edition. Springer-Verlag. 1993:(35):1581-602.

3. Hayasaka K, Shiono S, Yanagawa N. Multiple Endotracheal Metastases of Lung Cancer after Bronchoscopic Intervention. Intern Med. 2018;57(6):845-7.

4. Functional Evaluation before and after Interventional Bronchoscopy. Henri G. Colt, Bollinger CT, Mathur PN (eds): Interventional Bronchoscopy. Prog Respir Res Basel, Karger. 2000;30:55-64.

5. Petrou M, Goldstraw P. The management of tracheobronchial obstruction: a review of endoscopic techniques. Eur J Cardiothorac Surg. 1994:8(8):436-41.

6. Pierce RJ, Mestitz H, Simpson LW, Daniel FJ. Endobronchial resection with the Nd-YAG laser-two years experience in an Australian unit. Aust $\mathrm{N} Z \mathrm{~J}$ Med. 1990;(2):120-6.
Ready to submit your research? Choose BMC and benefit from:

- fast, convenient online submission

- thorough peer review by experienced researchers in your field

- rapid publication on acceptance

- support for research data, including large and complex data types

- gold Open Access which fosters wider collaboration and increased citations

- maximum visibility for your research: over $100 \mathrm{M}$ website views per year

At $\mathrm{BMC}$, research is always in progress.

Learn more biomedcentral.com/submissions 